\title{
Audiencias creativas y cibermundos: ¿Qué hacen los usuarios cuando una plataforma cierra?
}

\author{
Sormenezko audientziak eta zibermunduak: \\ Zer egiten dute erabiltzaileek plataforma \\ batek ixten duenean?
}

\section{Creative audiences and cyberworlds: What users do when a platform closes?}

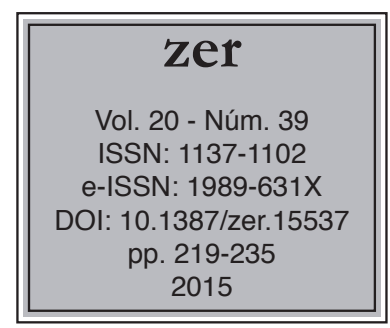

\section{Israel Márquez ${ }^{1}$}

Recibido el 24 de enero de 2014, aceptado el 16 de noviembre de 2015.

\section{Resumen}

Este artículo analiza las consecuencias del cierre de la plataforma digital There.com y las actividades de los usuarios tras este suceso. Se trata de uno de los cibermundos sociales más populares, junto con Second Life y Habbo. El estudio demuestra que, ante una situación crítica como es el cierre de una plataforma digital, las audiencias se revelan como especialmente creativas, participativas y colaborativas en la búsqueda de nuevos espacios en los que seguir en contacto y restablecer su comunidad, lo cual pone de manifiesto el carácter sólido, estable y duradero de los vínculos y relaciones tejidas en internet.

Palabras clave: Internet, cibermundos, redes sociales, etnografía, comunicación, comunidades virtuales.

\section{Laburpena}

Artikulu honek There.com plataforma digitalaren itxieraren ondorioak zein itxiera osteko erabiltzaileen ekintzak aztertzen ditu. Plataforma hori zibermundu ospetsuenetarikoa da, Second Life eta Habbo-rekin batera. Azterketak adierazten du plataforma digital batek ixten duenean audientziak bereziki sortzaileak, partehartzaileak eta kolaboratzaileak agertzen direla, komunitatea berrezartzeko eta berriro harremanetan egoteko beste guneak

${ }^{1}$ Universidad Complutense de Madrid, isravmarquez@gmail.com 
bilatzeko asmoz. Horrek agerian uzten du interneten ehundutako loturak eta harremanak sendoak, egonkorrak eta iraunkorrak direla.

Gako-hitzak: Internet, zibermunduak, sare sozialak, etnografia, komunikazioa, komunitate birtualak.

\section{Abstract}

This paper analyses the consequences of a digital platform closure and the activities of the users after this event. The starting point is the closure of the cyberworld There.com, one of the most popular social cyberworlds along with Second Life and Habbo. The study shows that audiences immersed in a situation of closure or end of a platform are particularly creative, participatory and collaborative in the search of new spaces in which keeping in touch and restoring their community, highlighting the solid, stable and enduring nature of the links and relationships woven on the Internet.

Keywords: Internet, cyberworlds, social networks, ethnography, communication, virtual communities. 


\section{Introducción}

\section{1. ¿Mundos virtuales o cibermundos?}

Los espacios digitales sobre los que nos vamos a ocupar en este trabajo se conocen comúnmente con el nombre de "mundos virtuales" (virtual worlds, en la literatura anglosajona), y es este el término más utilizado a la hora de describirlos. Sin embargo, esta expresión no está exenta de problemas, por todas las connotaciones negativas que la palabra "virtual" trae consigo, y es por eso que en este artículo optaremos por una denominación alternativa para referirnos a tales espacios de internet: la palabra "cibermundos"2.

La principal razón para este cambio de denominación es que la proliferación de usos de la expresión "realidad virtual", "mundo virtual", o simplemente "virtual", ha terminado por privarle de cualquier sentido preciso. Como señala Castañares (2011: 59), lo virtual se ha convertido en un término-saco que se usa para aludir tanto a todo lo que de algún modo tenga "algo que ver con las tecnologías digitales como para aquello que no se considera real, ya porque se trata de algún ente de ficción o de alguna realidad que no se considera plenamente realizada". La expresión "realidad virtual" tuvo un significado muy preciso en el contexto de las nuevas tecnologías digitales de los años 80, cuando empezaron a surgir toda una serie de aparatos que tenían la facultad de transportar al usuario a un mundo artificial diferente del mundo físico por medio de tecnologías protésicas (cascos, gafas, guantes, visores) que lo aislaban de la "realidad real" circundante. Este fue también el sentido de "realidad virtual" que conquistó el imaginario sociocultural de la gente, ya que esos experimentos tecnológicos llevados a cabo en laboratorios científicos empezaron a aparecer posteriormente en novelas, producciones televisivas y películas de gran éxito comercial como El cortador de césped, Johnny Mnemonic, Desafío total o Matrix.

Junto a este sentido técnico o informático de lo virtual, existen un uso corriente y otro filosófico (Lévy, 2007). En su uso corriente, la palabra "virtual" se emplea a menudo para significar la irrealidad, lo falso, lo inexistente, cuyo origen está en la utilización del término por la óptica a partir del siglo XVIII. Este uso establece una clara oposición binaria entre lo real y lo virtual, generando el pensamiento (aún presente en nuestros días) de que una cosa debe ser o bien real, o bien virtual, pero no puede poseer las dos cualidades a la vez. Lo virtual es, pues, lo opuesto a lo real, lo que parece real sin serlo completamente, y por tanto, lo irreal, falso, ficticio, doble, aparente, inexistente, etc. Es esta concepción de lo virtual la que hace que el término difícilmente deje de evocar una noción de irrealidad, y siempre con una marcada connotación peyorativa.

No obstante, tal y como señalan algunos teóricos como Deleuze, Serres, Lévy o Zizek, lo virtual no se opone a lo real sino a lo actual. Es el uso filosófico del término, donde la realidad no es la otra cara de lo virtual, sino de lo actual. Quizás sea Pierre

\footnotetext{
Al hacer uso de este término, entramos en relación con otros autores que han optado por esta nomenclatura en el marco de los estudios específicos sobre cibermundos (Klastrup y Tosca, 2004), así como con aquellos otros autores dentro el vasto mundo de estudios sobre Internet, realidad virtual y cibercultura que prefieren el prefijo "ciber" a otros como "virtual" o "digital", como por ejemplo Jones $(1995,2003)$ y su idea de "cibersociedad".
} 
Lévy el máximo responsable de haber expandido este uso filosófico de lo virtual en libros como ¿Qué es lo virtual? (Lévy, 1999). No señalaremos aquí todas y cada una de las dificultades que la concepción de este autor plantea en un marco de investigación como el nuestro. Remitimos para ello a otros trabajos que han tratado expresamente este complejo problema (Echeverría, 2000; Castañares, 2011). Sí mencionaremos, sin embargo, que la principal dificultad de esta idea de lo virtual es que Lévy encuentra virtualidades por todas partes y el concepto deviene omnicomprensivo, perdiendo toda precisión semántica. Tan virtual es, para Lévy, un texto lingüístico como las bibliotecas, las cuentas bancarias, los registros de la propiedad y el ciberespacio. El problema, como subraya acertadamente Echeverría (2000: 127), es que "dicha noción poco tiene que ver con las tecnologías concretas de realidad virtual que se han desarrollado en la segunda mitad del siglo XX", de modo que, coherentemente con las tesis de Lévy, podríamos decir que "cualquier tendencia o proyecto es virtual, como también lo sería el deseo, la búsqueda, la aventura [...] Casi todo en la naturaleza, las personas y las sociedades serían virtualidades".

Es por todo ello que consideramos la palabra "virtual" problemática para ser utilizada como concepto analítico y descriptivo en nuestro trabajo, ya que su uso conlleva toda una serie de implicaciones que poco o nada tienen que ver con el tipo de experiencias que aquí nos interesan: aquellas relacionadas con las tecnologías digitales. Es por eso que preferimos emplear la palabra "cibermundos" para referirnos a lo que en el ámbito anglosajón se conoce como "mundos virtuales". Parte de esta elección viene de lo señalado anteriormente con respecto a la confusión que gira alrededor de la noción de lo "virtual" y al hecho de que un término como "cibermundos" nos permite prescindir de esta palabra y de toda la polisemia que la rodea.

Pero también creemos que la noción de "ciber" conlleva toda una serie de ideas que permiten acercarnos al fenómeno que queremos estudiar de una manera más precisa y correcta. Por ejemplo, el prefijo "ciber" parte del griego kybernetes, que se refiere al timonel, el cual gobierna la embarcación. Este sentido es fundamental a la hora de hablar de "cibermundos" y de preferir esta expresión a otras, ya que señala un aspecto a menudo olvidado en los estudios sobre el tema: el hecho de que estos mundos son controlados por las empresas que las albergan, las cuales ejercen un determinado "orden" y "gobierno" sobre ellos y, por ende, sobe nosotros mismos como usuarios. Los responsables de los cibermundos son los encargados de tomar las decisiones principales en torno a los espacios que dirigen y gobiernan, pudiéndolos abrir, modificar, cerrar e incluso reabrir cuando quieran. Es precisamente este control el que hace que se produzcan prácticas tan interesantes como protestas y manifestaciones de los usuarios en el interior del mundo, e incluso fuera de él, en otros espacios de la red. A la hora de hablar de ciberdiásporas, un concepto que introducimos en este trabajo a partir de la idea de "diáspora virtual" propuesta por Pearce (2009), este aspecto será fundamental, ya que el cierre de un determinado cibermundo apela a esta idea de control y genera toda una serie de protestas, peticiones, movilizaciones y alternativas de los propios usuarios ante la decisión de los creadores.

Por otro lado, esta idea de control también puede relacionarse con la acción que realizamos nosotros mismos al "dirigir" a nuestros avatares, quienes responden eficazmente a nuestras operaciones con el ordenador, aunque dentro de otro importante sistema de control: el impuesto por los propios diseñadores del cibermundo en el 
software que lo sustenta, un aspecto también olvidado en gran parte de la investigación académica sobre estos y otros medios digitales. ${ }^{3}$

\section{2. ¿Qué son los cibermundos?}

Aunque la investigación académica sobre cibermundos es relativamente reciente, en especial aquella dedicada a los cibermundos tridimensionales que dominan el panorama actual, son varios los autores procedentes de distintas disciplinas (comunicación, psicología, educación, antropología, etc.) que han intentado ofrecer una definición de los mismos, aun con las complejidades que un intento de este tipo, y más en un campo de investigación tan reciente, conlleva. Klastrup (2003: 27), por ejemplo, define los cibermundos como "una representación persistente en línea que contiene la posibilidad de una comunicación sincrónica entre usuarios, y entre los usuarios y el mundo, dentro de un espacio diseñado como un universo navegable"4. Boellstorff (2008:17), desde una posición más cercana a la antropología, los define como "lugares de cultura humana realizados por programas informáticos a través de internet". Castronova (2005: 22) define lo que él prefiere llamar "mundos sintéticos" como "cualquier espacio físico generado por ordenador, representado gráficamente en tres dimensiones, que puede ser experimentado por muchas personas a la vez". Para Malaby (2009: 2), los cibermundos proporcionan un "espacio persistente, abierto, compartido y tridimensional en el que los usuarios pueden interactuar, típicamente a través de avatares (cuerpos virtuales que se mueven y actúan dentro del mundo)". Nardi (2010: 18), por último, los define como espacios en los que los participantes 1) crean un carácter animado, 2) mueven el carácter en un espacio tridimensional, 3) disponen de medios para comunicarse con otros, y 4) tienen acceso a una rica variedad de objetos digitales.

En todas estas definiciones existen algunos elementos comunes, como por ejemplo la necesidad de acceder a los cibermundos a través de internet, el empleo de avatares como "sustitutos" o encarnaciones digitales del usuario, la posibilidad de interacción y comunicación entre avatares, la tridimensionalidad propia de estos espacios, y su persistencia, esto es, el hecho de que permanezcan siempre "encendidos" y que sea capaz de desarrollarse sin nuestra presencia en él.

Teniendo en cuenta estos elementos, señalamos a continuación nuestra propia definición de cibermundo, que será la siguiente: los cibermundos son espacios sociales persistentes generados por ordenador y representados gráficamente en tres dimensiones a los que los usuarios pueden acceder a través de internet mediante representaciones digitales conocidas como avatares para comunicarse e interactuar con otros usuarios y con los objetos que se encuentran en su interior. Creemos que una definición como ésta reúne todos aquellos elementos necesarios para poder

\footnotetext{
3 En los últimos años, sin embargo, han surgido una serie de autores agrupados bajo la expresión "software studies" o "estudios sobre el software" que reclaman un cambio de paradigma en el estudio de los medios digitales, haciendo del software el principal elemento de análisis. Los software studies advierten una infravaloración de la programación informática por parte de los estudios y teorías sobre los nuevos medios aun cuando la programabilidad, es decir, el software, es la cualidad fundamental de los medios digitales (Manovich, 2005, 2013).

4 Todas las traducciones del inglés son del autor.
} 
hablar de cibermundos, en especial de los cibermundos actuales, la mayoría de los cuales incluyen una representación corporal del avatar en un espacio representado gráficamente en tres dimensiones, tal y como podemos ver en títulos paradigmáticos como Second Life o World of Warcraft.

Los cibermundos constituyen hoy en día una de las disciplinas propias de los denominados "nuevos medios de comunicación" (Manovich, 2005), junto con otras como los sitios web, la Realidad Virtual, el multimedia, los vídeojuegos, las instalaciones interactivas, la animación por ordenador, el vídeo digital, el cine, o las interfaces entre hombre y ordenador. Son también, como los vídeojuegos (medio con el que a veces se confunden), un ejemplo de nueva "forma cultural" nacida a raíz de la informatización de la cultura, esto es, una forma cultural cuya especificidad reside en estar basada en el ordenador y en el lenguaje digital. La cibercultura, en este sentido, no sólo redefine formas culturales existentes (el cine, la fotografía, el vídeo, etc.), sino que también genera otras específicas, siendo los cibermundos y los vídeojuegos ejemplos paradigmáticos de ello.

Si bien la investigación académica sobre cibermundos se ha desarrollado rápidamente durante los últimos años, en especial en Estados Unidos y en algunos países europeos (los países escandinavos, principalmente), no existe en los países de habla hispana una extensa literatura sobre ellos, o la que hay se ha centrado en aspectos muy concretos de los mismos, como por ejemplo sus potenciales educativos $^{5}$. De ahí la necesidad de profundizar en el estudio de estos espacios digitales indispensables para entender la evolución de la cibercultura, pues en ellos se están produciendo muchas de las dinámicas, tensiones y problemáticas de nuestro ya omnipresente mundo digital.

\section{Metodología}

Este trabajo presenta algunos resultados derivados de un proyecto de investigación etnográfica sobre cibermundos realizado durante más de tres años entre España, Estados Unidos y Dinamarca. Siguiendo las razones aportadas en el apartado anterior, emplearemos el término "ciberetnografía" en lugar de otros como "etnografía virtual" (Hine, 2004) para referirnos al proceso de investigación etnográfica llevado a cabo en internet. El prefijo "ciber" es de nuevo acertado en este caso puesto que implica cierta idea de control y gobierno que es inherente a toda investigación etnográfica (el etnógrafo siempre "controla" sus datos y "dirige" la investigación), y que también se manifiesta en la utilización de programas y servidores gestionados por administradores y demás agentes informáticos, quienes ejercen un control total sobre ellos y permiten una mayor o menor libertad de movimientos a los ciberetnógrafos.

Como es sabido, la etnografía es un método de investigación social mediante el cual observamos y participamos en la vida diaria de personas y grupos durante un cierto período de tiempo, registrando sus actividades y quehaceres con el objetivo de conocer su comportamiento social y poder realizar un retrato coherente de su cultura.

\footnotetext{
5 Un ejemplo de este tipo de estudios centrados en el potencial educativo de los cibermundos y otros espacios similares como los vídeojuegos y la Realidad Virtual es el monográfico titulado "Comunicación y Educación inmersiva", editado por la revista de investigación española Icono 14 (Vol. 9, núm. $2,2011)$.
} 
La aplicación de este método de investigación social al estudio de los cibermundos puede ayudarnos a comprender las prácticas cotidianas que tienen lugar en estos nuevos espacios de internet, observando con detalle las formas en que se experimentan y adquieren significado entre sus participantes.

La mayoría de las ciberetnografías se han centrado en el estudio de espacios delimitados dentro de internet, por ejemplo, comunidades o grupos de usuarios dentro de canales de chats, listas de discusión, grupos de noticias, foros, MUDs, redes sociales, etc. Esta tendencia a delimitar espacialmente el objeto de estudio también ha sido seguida en las etnografías sobre cibermundos, la mayoría de las cuales se han centrado fundamentalmente en el estudio de uno sólo: Everquest (Castronova, 2005; Taylor, 2006), Second Life (Boellstorff, 2008), World of Warcraft (Nardi, 2010).

Sin embargo, el tipo de ciberetnografía que presentamos aquí es diferente, puesto que no se basa en el estudio de un solo cibermundo sino de varios de ellos, e incluso de otras plataformas digitales como redes sociales y foros. Llamamos a este tipo de etnografía, siguiendo a Pearce (2009), "ciberetnografía multi-situada", la cual implica que el etnógrafo realice inmersiones en más de un lugar dentro de internet, siguiendo las actividades y movimientos de la comunidad estudiada a través de varias plataformas de la red e incluso en contextos presenciales. El concepto de "ciberetnografía multi-situada" es una traducción al ámbito digital de la "etnografía multi-situada" propuesta por George Marcus, la cual supone un modo de trascender la vieja idea de situar el trabajo etnográfico en un espacio o zona geográfica delimitada y apostar en su lugar por "examinar la circulación de significados culturales, objetos e identidades en un espacio-tiempo difuso" (Marcus, 1995: 96). Este autor reemplaza la imagen etnográfica tradicional de la residencia por la del seguimiento de personas y objetos por distintos lugares, y ello por rutas que menudo no pueden prefigurarse y a las que el etnógrafo tendrá que hacer frente con una nueva sensibilidad etnográfica de carácter más móvil y fluido. Se trata de volcar la atención no tanto en el "estar ahî" como en el "llegar ahî" (Clifford, 2008), mediante diseños de investigación y trabajos de campo que implican exploraciones en más de un lugar y que están enfocados fundamentalmente hacia el seguimiento de las conexiones y los flujos culturales.

Dado que la comunidad de usuarios objeto de estudio se vio inmersa en un proceso de dispersión digital como consecuencia del cierre del cibermundo en el que se habían conocido y establecido lazos y relaciones, la estrategia multi-situada se reveló como la más conveniente y adecuada a la hora de seguir los intentos de reconfiguración de la comunidad tras este cierre y su búsqueda conjunta de un nuevo ciberhogar. Más allá de su aplicación concreta a este caso de estudio, pensamos que este tipo de mirada etnográfica es especialmente relevante para el estudio del mundo contemporáneo y, sobre todo, coherente con él, ya que si por algo se caracteriza la realidad actual es por la movilidad de personas, comunidades, culturas, objetos, narrativas, biografías, conflictos, etc., tanto en contextos físicos o presenciales como en los múltiples espacios digitales de internet. La tarea del (ciber)etnógrafo multisituado es, pues, ofrecer un retrato coherente de este panorama tan heterogéneo explorando cómo se producen los vínculos, redes y conexiones entre personas, y cómo se van negociando y transformando a lo largo del tiempo y en los diferentes espacios por los que se manifiestan y desarrollan. 


\section{Análisis y resultados}

\subsection{Memorias de There.com}

El punto de partida de este trabajo es el cierre del cibermundo There.com el día 9 de marzo de 2010. A partir de este cierre se plantea una pregunta de investigación fundamental: ¿Qué ocurre cuando un cibermundo cierra?, la cual puede llevarse a un dominio ontológico mucho mayor: ¿Qué ocurre cuando una plataforma digital cierra? ¿Qué hacen los usuarios ante esta situación? ¿Hay vida más allá de la plataforma que muere? Los estudios sobre cibermundos y otros espacios de internet suelen llevarse a cabo mientras estos espacios están abiertos. Tales espacios interesan mientras están vivos y los usuarios se relacionan diariamente en su interior. No extraña, pues, que el estudio de qué ocurre cuando una plataforma digital cierra y qué hacen sus usuarios tras esta crítica situación haya sido muy poco investigado en el ámbito académico, salvo algunas notables excepciones (Pearce, 2009; Consalvo y Begy, 2011). ${ }^{6}$ Este trabajo viene a llenar este vacío mediante una investigación etnográfica realizada a raíz del cierre del cibermundo There y el seguimiento activo de sus usuarios tras este fatal acontecimiento.

There.com, o simplemente There, es un cibermundo social creado por Will Harvey y Jeffrey Ventrella que se lanzó al mercado en octubre del año 2003. Desde un primer momento, There ha sido descrito como el principal competidor de Second Life, aun sin llegar a alcanzar el éxito internacional de éste. Ambos cibermundos tienen mucho en común. Los dos se lanzaron en el año 2003, y los dos son cibermundos eminentemente sociales, donde no hay un objetivo prefijado de antemano, a diferencia de otros como el famoso World of Warcraft. Ambos cibermundos, junto con el finlandés Habbo, son los más populares dentro de los llamados cibermundos sociales.

El cibermundo There.com fue concebido como un lugar para la socialización entre avatares, "un escape online", como decía su página web, "donde puedes pasar el rato con tus amigos y conocer otros nuevos", "el mundo virtual online que es tu lugar de reunión de todos los días". Una diferencia con respecto a Second Life es que estaba más dirigido a una audiencia adolescente y juvenil. Así, mientras en Second Life la edad mínima para entrar son los 18 años, en There era 13. En este sentido, se trataba de un cibermundo mucho más controlado que Second Life, ya que debía cumplir con los estándares de contenido de un producto para menores de edad. Para ello, There utilizaba filtros para mantener el vocabulario inapropiado fuera de los chats textuales y debía revisar y aprobar todas las creaciones de los usuarios. Al igual que en Second Life, los usuarios podían crear sus propios objetos (ropa, vehículos, muebles, edificios, etc.) y venderlos a otros residentes para su uso en el cibermundo. Sin embargo, a diferencia de Second Life, cada objeto creado se

\footnotetext{
${ }_{6}$ Pearce estudia el caso del cierre del cibermundo Uru: Ages Beyond Myst -una extensión del popular juego de aventura gráfica Myst-, mientras que Consalvo y Begy analizan las consecuencias del cierre de otro cibermundo menos conocido, Faunasphere. Si bien Pearce analiza en su trabajo algunos aspectos de There.com debido a que varios miembros de la comunidad que estudiaba en Uru: Ages Beyond Myst se instalaron en él, no analiza el cierre de este cibermundo, el cual se produjo varios meses después de su investigación.
} 
sometía a un procedimiento de aprobación por parte de los responsables de There, quienes eran en última instancia los que decidían si ese objeto era apto para pasar a formar parte del cibermundo o no.

Al igual que en otros cibermundos, en There era necesario crear un avatar para acceder a su interior. Para ello, debíamos elegir el nombre y aspecto de nuestro avatar, que podía ser masculino o femenino. La elección del nombre y del género del avatar era muy importante puesto que eran los únicos elementos que no se podían modificar. Otros atributos como el color y estilo de pelo, la cabeza y otras partes del cuerpo, el color de piel, de ojos, la ropa, etc., podían cambiarse según nuestras preferencias. A través de sus avatares, las personas eran capaces de comunicarse en tiempo real utilizando el chat textual, el chat de voz, los mensajes privados, los emoticonos o la propia gestualidad del avatar.

El aspecto general de los avatares era muy peculiar en There ya que tenía un estilo caricaturesco, como de dibujo animado, que era una de las características fundamentales de este cibermundo. Así mismo, los avatares eran atractivos por defecto, con un aspecto veinteañero que los hacía parecer muy juveniles, algo que es común a la mayoría de cibermundos. Aun cuando intentáramos aumentar la edad de estos avatares cambiando algunos aspectos de su apariencia, siempre lucían un aspecto muy juvenil. El aspecto de cómic de los avatares se acentuaba mediante el recurso indicial al globo o bocadillo (conocido como chat balloon), el cual integraba gráficamente las palabras que el usuario tecleaba en su ordenador y mediante el cual se comunicaba con los demás avatares.

Todo el trabajo de comunicación no verbal estaba muy conseguido en There, y uno de los responsables de su creación, Jeffrey Ventrella, lanzó en 2011 un libro dedicado a explicar la importancia de este aspecto. El título del libro es bastante significativo a este respecto: "Virtual Body Language. The History and Future of Avatars: How Nonverbal Expression is Evolving on the Internet. De hecho, como recuerda Ventrella (2011), eligieron el nombre de "There" porque esta palabra transmite un sentido de lugar que es central en la experiencia de diseño que querían conseguir: un lugar de encuentro digital donde los elementos espaciales de la interacción corporal fueran fundamentales para la experiencia.

Otro aspecto interesante de There y que lo diferenciaba completamente de otros cibermundos es que era literalmente un mundo, una esfera. No existían límites que frenaran el desplazamiento de los avatares y era posible recorrer el espacio hasta llegar al punto donde se empezó, dando la vuelta completa a la esfera. En este sentido, el desplazamiento y la exploración eran actividades fundamentales de este cibermundo. Es por ello que There contaba con varios vehículos que los usuarios utilizaban para recorrer el espacio del mundo, y este es otro de los aspectos que lo diferenciaba de otros cibermundos similares, los cuales cuentan en general con menos posibilidades de elección en este sentido. There contaba con varios modos de transporte, entre ellos el popular "hoverboard" que adquirías nada más registrarte, una especie de tabla de surf o de skate que se cierne a poco metros del suelo, como la que aparecía en la segunda película de la famosa saga Back to the Future, con la que guarda un especial parecido.

Otros vehículos famosos en There eran los denominados "buggies" o "areneros" (los cuales se usaban principalmente para desplazarse por la arena), y otros vehículos 
similares al "hoverboad" que también dejaban al avatar suspendido en el aire, tales como la "hoverbike", la "hoverboat", los "hoverpacks" o los "Bacios", una especie de scooters que se levantaban a unos metros del suelo y se desplazaban a gran velocidad. También había coches de carreras denominados respectivamente "SUV", "coupe", "muscle car" y Scion", que eran muy famosos entre los residentes y que se podían personalizar a gusto de cada uno. Todos estos vehículos funcionaban como extensiones de la personalidad de cada avatar, tal y como McLuhan se encargó de advertir con respecto a los coches reales, esas "novias mecánicas" que son todo un medio de comunicación social:

El coche se ha convertido en una prenda de vestir sin la cual nos sentimos inseguros, desnudos e incompletos en el conjunto urbano. [...] El hecho básico y obvio del auto-móvil es que [...] es una extensión del hombre que convierte a su conductor en un superhombre. Es un medio caliente, explosivo, de comunicación social (McLuhan, 1996: 227-231).

Todos estos vehículos -la libertad para viajar en ellos, de personalizarlos, así como de organizar carreras para divertirse con los amigos-, eran recordados por los ex miembros de There como una de las características que más echaban de menos de este cibermundo y que eran incapaces de encontrar en otros, en todos aquellos cibermundos y espacios digitales que se vieron obligados a explorar y evaluar una vez que fueron expulsados de su "hogar" digital.

\subsection{El cierre de un mundo y sus consecuencias}

There dejó de funcionar el 9 de marzo de 2010 a las 11:59 de la noche, hora del Pacifico, la zona horaria donde las oficinas de este cibermundo estaban localizadas. La noticia del cierre fue anunciada una semana antes por Michael Wilson, fundador de Makena Technologies, la compañía detrás de There. La noticia fue recibida como un duro golpe por parte de todos aquellos que formaban parte de este cibermundo, no sólo por sus usuarios sino por los mismos empleados que trabajaban en él. El poco tiempo transcurrido entre la noticia del cierre y la fecha en que el servicio dejaría de funcionar, tan sólo una semana después, aumentó la sensación de infelicidad e impotencia por parte de los usuarios, quienes se quedaron perplejos al conocer la noticia y veían injusto el poco tiempo que se les daba para realizar sus últimas incursiones en el que había sido su lugar de reunión durante años. Wilson argumentaba problemas económicos que hacían inviable el sostenimiento de There, señalando una realidad a menudo olvidada en los estudios sobre este tipo de espacios, el hecho de que son, antes que cualquier otra cosa, negocios: "There es un negocio, y un negocio que no puede sostenerse a sí mismo no funciona", como decía Wilson en su anuncio. 
Imagen 1. Cierre de There.com.

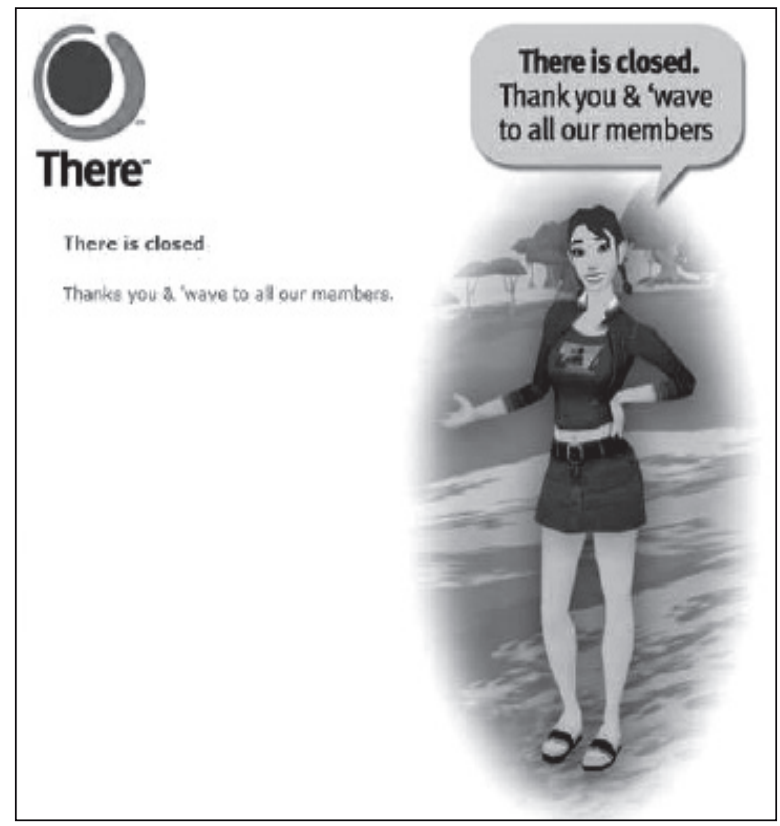

Fuente: Makena Technologies.

Tan pronto como la noticia del cierre se hizo pública, There empezó a detener de manera progresiva toda la actividad relacionada con el cibermundo: registro, actualizaciones, creaciones de usuario, transacciones económicas, etc. No sólo empezó a detenerse toda la actividad que tenía lugar en el interior del cibermundo, sino también aquella que se desarrollaba en espacios auxiliares como el foro oficial de There. En él, muchos miembros molestos y enojados por la decisión de la compañía escribieron diversos posts donde mostraban su descontento y pedían explicaciones, pero pronto vieron cómo este espacio también desaparecía puesto que There decidió cerrarlo y eliminar toda la información recogida en el mismo. Los miembros de There empezaron a ser conscientes de que todo el tiempo, esfuerzo y dinero que habían dedicado a este cibermundo durante los últimos años empezaba a esfumarse en apenas una semana.

\subsection{Vida más allá del cierre}

Al ver que el foro de There desaparecía, muchos usuarios se trasladaron a Thumdar. com, una red social creada en abril de 2004 precisamente por un ex miembro de There. Los miembros de There se sirvieron de esta plataforma para exponer sus críticas a la decisión de la compañía y para mostrar sus sentimientos, emociones y pensamientos sobre el cierre. Estos usuarios empezaron a visitar y dejar sus comentarios no sólo en Thumdar sino en múltiples lugares de internet, algunos de ellos creados también por ex miembros de este cibermundo (One There, There Worlds, Life afterThere, etc.). 
Algunas publicaciones de tecnología y entretenimiento también se hicieron eco del cierre de There, y junto a la noticia de los periodistas encargados de redactar los artículos aparecían comentarios de miembros de este cibermundo expresando su malestar por el acontecimiento y el significado que este espacio tuvo en sus vidas. En estos y otros ciberlugares, los usuarios se presentaban con el nombre que tenían en este cibermundo y añadiendo la palabra "There", "Thereian" o "Therian" al final del mismo, ${ }^{7}$ por ejemplo, BanskyThere, PunkThereian, Marcy_Therian, etc., demostrando así su sentido de pertenencia a este cibermundo, aun cuando ya no existiera. Un usuario decía lo siguiente en un comentario a uno de estos artículos relacionados con la noticia del cierre de There:

"He sido miembro de There desde el año 2004. Es un día triste para los mundos virtuales porque There ere verdaderamente único. Los avatares y sus reacciones naturales, su respiración y sus movimientos, hacía que la gente se identificara con sus avatares mucho más que en cualquier otro mundo.

Soy miembro de diferentes mundos virtuales (SL, WoW, Blue Mars... por nombrar sólo algunos), pero NINGUNO me ha atraído y mantenido tanto como There, y es There al que siempre consideraré mi HOGAR.

There.com era un lugar mucho más especial de lo que sus creadores llegaron a imaginar."

El 12 de marzo de 2010, There eliminó también los vídeos que tenía alojados en YouTube, una decisión que sorprendió enormemente a sus ya ex residentes. Sin embargo, cuando los miembros conocieron la fatal noticia ellos mismos empezaron a subir vídeos y secuencias de fotografías de There al popular servicio de alojamiento de vídeos. La mayoría de ellos reflejaban los últimos días de los avatares en este cibermundo y funcionaban a modo de recordatorio del mismo. El vídeo "Memories of There" es un buen ejemplo de ello. El vídeo fue realizado por un usuario de There que se encargó de reunir a varios avatares durante la última semana de actividad del cibermundo para que narraran sus mejores momentos en There. El vídeo presentaba a varios avatares mirando a cámara y narrando sus experiencias por medio de las voces reales de las personas que los manejaban. Entre los comentarios de los usuarios podían leerse fragmentos como este: "Este vídeo acaba de hacerme llorar", o este otro: "Echo de menos There. Todavía no puedo creer que haya cerrado. Tenía muy buenos amigos allí", los cuales se acompañaban casi siempre de emoticonos de tristeza: :'(

Este flujo de actividad en diversos lugares de internet durante los días posteriores al cierre de There pone de manifiesto el esfuerzo que los propios usuarios realizaron por permanecer juntos, haciendo un uso intensivo de las diversas herramientas de la web 2.0 con el fin de reunirse y compartir la experiencia de manera colectiva. De

7 Los usuarios de There se denominaban a sí mismos "Thereians" o "Therians" indistintamente. He optado por traducir ambos términos por la palabra "thereiano". 
alguna manera, el conflicto generado en torno a la decisión de la compañía de cerrar There, más que debilitar los lazos del grupo, sirvió para fortalecerlos, lo cual pone de manifiesto esa función integradora del conflicto que advirtieran autores como Simmel (1955) y Coser (1956). Para estos autores, el conflicto no sólo tiene efectos destructores, sino que también puede funcionar como una fuerza integrativa y cohesiva potente capaz de aumentar la solidaridad interna del grupo y reafirmar sus fronteras y su sentimiento de identidad.

Pero si hay un sitio que tuvo una importancia especial durante las semanas siguientes al cierre de There.com ese fue la red social Facebook, la cual estaba alcanzando una gran popularidad dentro de la comunidad There por ser el lugar donde se estaba desarrollando una mayor comunicación entre sus miembros y donde más grupos de ex usuarios de There se estaban formando. La mayoría de los usuarios se habían hecho una cuenta específica en Facebook vinculada al nombre y aspecto de su avatar en There. Muchos acompañaban su nombre añadiendo la palabra "There", "Thereian" o "Therian" al final del mismo, como habían hecho en otros lugares de internet, y añadiendo incluso un logotipo de There a su foto de perfil, cuya imagen era la del aspecto de su avatar en There. Facebook servía como lugar de reunión y como plataforma para expresar su situación y volcar sus sentimientos sobre la pérdida del cibermundo. Como decía un usuario: "There era un lugar especial. Era mi casa. No puedo creer que haya cerrado", y como expresaba otro: "Cuando There murió, una parte de mí también murió".

Este tipo de reacciones de pena y tristeza son comunes cuando algo llega a su fin, tanto en el ámbito "real" -fin de una pareja, de una amistad, de un viaje o estancia en una ciudad, etc.- como en el "ficcional". Respecto a este último caso, son conocidas las reacciones de las personas ante el doloroso cierre de una novela, una película o una serie de televisión. En este sentido, Janet Murray (1999: 187), señala que el final de una obra, su conclusión, es siempre dolorosa, pues supone "romper el trance de inmersión y salir del mundo envolvente al aire frío de la realidad". El final de una historia puede ser doloroso tanto para los creadores como para la audiencia, sobre todo en narrativas enciclopédicas como los ciclos novelescos, series de televisión ("Lost" sería un ejemplo paradigmático en los últimos años), o sagas cinematográficas, de cómics o de videojuegos. Da igual que se trate de productos ficcionales, pues sabemos que las ficciones - entre las que se incluyen todas aquellas relacionadas con lo digital- pueden desatar en nosotros reacciones tan verdaderas, reales, intensas y profundas como las que se producirían en situaciones presenciales.

Por lo tanto, es indiferente que las reacciones que provocó el cierre de There en su audiencia se produjeran en torno a algo que pudiera parecer banal a ojos de los demás (un cibermundo). Lo importante es que estos sentimientos eran reales para sus usuarios, y así lo comunicaban a los demás, mediante palabras y actos que eran de todo menos ficcionales y que actuaban como una manera de desahogarse y compartir su pena colectivamente, una pena experimentada de manera muy real. Los usuarios manifestaban así un sentido de identidad colectiva, claramente visible en los nombres terminados en "There" que utilizaban en sitios como Facebook, o la inclusión del símbolo de There en algunas de sus fotos de perfil. Igualmente, esta identidad colectiva no era ficticia sino muy real, y signo de ello es todo el esfuerzo que los "thereianos" hicieron para permanecer juntos tras el cierre de su cibermundo. 


\subsection{En busca de un nuevo ciberhogar}

Lo interesante, sin embargo, es que estos usuarios utilizaron las plataformas de la web 2.0 para reunirse y buscar juntos un nuevo cibermundo, pues tales plataformas no les ofrecían la experiencia tridimensional e inmersiva propia de los cibermundos. Facebook y otros sitios de internet servían para comunicarse entre sí y mantenerse en contacto pero su propia naturaleza es muy diferente a la de los cibermundos: no son espacios tridimensionales y no permiten el tipo de interactividad e inmersión propios de éstos. Los usuarios echaban de menos poder relacionarse mediante su avatar, poder explorar el cibermundo, poder moverse, poder construir objetos, en definitiva, todo aquello que la propia mecánica de sitios como Facebook, Thumdar o YouTube no permitía.

Así pues, varios grupos de personas decidieron reunirse y explorar juntos otros cibermundos con el objetivo de encontrar el que más se pareciera a There y poder restablecer allí su comunidad. Entre los cibermundos que los "thereianos" comenzaron a explorar se encontraban los siguientes: Second Life, Twinity, Onverse, Blue Mars, IMVU, Kaneva, Frenzoo, Utherverse, Gaia Online, Moove o vSide. En este sentido, la experiencia de estos usuarios puede describirse como una diáspora, una "diáspora virtual" (Pearce, 2009), o mejor aún, una ciberdiáspora, ya que implica un proceso de dispersión digital a través de internet propiciado por la pérdida del ciberhogar, por el cierre de un mundo considerado como una "casa" por sus propios usuarios, como veíamos en un fragmento anterior. La palabra "diáspora" procede del griego -dia " "a través de", y speirein, "dispersar, traducir". Diáspora es una "dispersión desde". De ahí que la palabra exprese una noción de centro, un locus, un "hogar" desde el que se produce la dispersión. Igualmente, la palabra evoca imágenes de múltiples viajes (Brah, 2011), aquellos que lleva a cabo la comunidad diaspórica en busca de un nuevo hogar, tal y como estaban haciendo los ex miembros de There.

El cierre de There, la pérdida del ciberhogar, del lugar de origen, hizo que la comunidad de usuarios que habitaban en él se vieran desplazados, situados en una condición de "sin hogar" en el espacio digital, expresión que muchos de ellos empleaban. Thumdar, YouTube o Facebook, actuaron en un principio como una especie de "balsas" en las que permanecer unidos durante el desconcierto inicial. Pero el objetivo era encontrar un tipo de experiencia similar a la que tenían en There, una construida en base a la representación tridimensional y la interactividad y gestualidad propia de los avatares.

Fue así como los ex miembros de There empezaron a registrarse y frecuentar otros cibermundos. En ellos, los propios usuarios empezaron a construir espacios que traducían o "remediaban" (Bolter y Grusin, 1999) el mundo de There, así como objetos que recordaban a este cibermundo, como camisetas estampadas con su símbolo. Durante los primeros meses que siguieron al cierre de There, sus usuarios estuvieron dispersos entre varios de estos cibermundos, pasando intermitentemente de unos a otros y explorando y explotando sus posibilidades. Sin embargo, con el paso del tiempo, la mayoría de "thereianos" acabaron reuniéndose y concentrándose en Second Life, el cual ofrecía mayores posibilidades que el resto de cibermundos: una comunidad más diversa, mayores posibilidades de creación, más lugares que visitar, más posibilidades de personalización del avatar, de creación de espacios y 
objetos, etc. Los "thereianos" reconocían que les gustaba Second Life porque en él encontraban una experiencia cercana a la de There, ${ }^{8}$ especialmente en lo relativo a la creación de contenido propio, y también disfrutaban de nuevos aspectos como las posibilidades infinitas de confección del avatar y la libertad de actuación. En There había muchas personas interesadas en la creación de contenido y Second Life les proporcionaba una plataforma muy parecida para seguir experimentando con su imaginación y creatividad, así como la posibilidad de compartir sus creaciones con los demás. Así mismo, esta libertad de actuación facilitaba la realización de prácticas y la creación e incorporación de símbolos y referencias relacionados con There, provocando que los avatares se sintieran como en casa, como en ese hogar que les había sido arrebatado. El resultado fue que muchos de ellos acabaron haciendo de Second Life su nuevo ciberhogar, tal y como reconocía claramente una informante: "El hogar está donde tu está tu corazón. Y mi corazón ahora está en Second Life”.

\section{Discusión y conclusiones}

A lo largo de este artículo hemos presentado las consecuencias derivadas del cierre de una plataforma digital -en este caso, un cibermundo- a partir de una investigación basada en una metodología etnográfica "multi-situada" que nos ha permitido seguir a la comunidad y los usuarios objeto de estudio por varios espacios de la red. El cierre de There, la pérdida del ciberhogar, del lugar de origen, hizo que la comunidad de usuarios que habitaban en él se vieran desplazados, situados en una condición de "sin hogar" en el espacio digital, expresión que muchos de ellos empleaban. En este sentido, hemos descrito la situación en la que estos usuarios se vieron inmersos como una ciberdiáspora, ya que es posible observar en ella un proceso de dispersión digital propiciado por la pérdida de este cibermundo, al igual que ocurre en las diásporas presenciales y sus procesos de desplazamiento y búsqueda de un nuevo hogar. Los esfuerzos de los "thereianos" por permanecer juntos tras el cierre de su cibermundo y por buscar un nuevo ciberhogar, son el reflejo del tipo de lazos y solidaridades fuertes, sólidas, estables y duraderas -y no ya efímeras, débiles y líquidas (Bauman, 2003)-, que pueden tejerse actualmente en internet, y en espacios concretos como son los cibermundos.

El caso analizado pone de manifiesto que, ante una situación crítica como el cierre de una plataforma, las audiencias se revelan como especialmente creativas, participativas y colaborativas en la búsqueda de nuevos espacios en los que seguir en contacto y restablecer su comunidad. Esto es consecuente con los resultados de otros trabajos que llegan a conclusiones semejantes (Pearce, 2009; Consalvo y Begy, 2012) y que ponen de manifiesto el hecho de que los usuarios forman lazos y relaciones fuertes y duraderas en el mundo digital, y estos lazos continúan más allá de la plataforma concreta en que se surgieron, expandiéndose hacia otras redes y espacios.

En este sentido, como ha señalado Arjun Appadurai (1996), la imaginación cotidiana también se pone de manifiesto en el aspecto creativo relacionado con las actividades sociales que implican la pérdida o el abandono de la propia situación, como ocurre en el caso del emigrante, quien "para serlo debe imaginar posibles vías

\footnotetext{
8 En el subapartado 2.1. ya quedaron establecidas algunas de las principales características de There. com como cibermundo y algunas de sus similitudes y diferencias con Second Life.
} 
de salida" (Peñamarín, 2007: 170). En este caso, el hecho de que los miembros de There perdieran su ciberhogar de origen hizo que imaginaran "otros cibermundos posibles" en los que restablecer su comunidad. Y no sólo cibermundos, sino otros espacios digitales como redes sociales, foros, sitios como YouTube, etc., los cuales utilizaron de una manera creativa para seguir juntos tras el cierre de There. Es decir, estos usuarios imaginaron, encontraron y establecieron sus propios medios para estar juntos, para seguir juntos tras una situación crítica como es la pérdida de una plataforma. Al hacerlo, reaccionaron activa, creativa y colaborativamente ante un hecho impuesto desde arriba, desde la compañía responsable de There y su decisión de cerrar el cibermundo. Este hecho sugiere que las audiencias se rebelan contra las decisiones corporativas de los espacios que habitan creando sus propias soluciones. Lo importante no es tanto "dónde estar juntos" sino simplemente "estar juntos", "seguir juntos", pues las relaciones, los lazos y las amistades importan más que el lugar donde surgieron. Y los usuarios saben cómo continuar y mantener estas relaciones.

\section{Referencias bibligráficas}

APPADURAI, Arjun (1996). Modernity at Large. Cultural Dimensions of Globalization. Minneapolis: University of Minnesota Press.

BAUMAN, Zygmunt (2003). Comunidad. En busca de seguridad en un mundo hostil. Madrid: Siglo XXI.

BOELLSTORFF, Tom (2008). Coming of Age in Second Life. New Jersey: Princeton University Press.

BOLTER, Jay David; GRUSIN, Richard (1999). Remediation: Understanding New Media. Cambridge: Cambridge University Press.

BRAH, Avtar (2011). Cartografías de la diáspora. Identidades en cuestión. Madrid: Traficantes de Sueños.

CASTAÑARES, Wenceslao (2011). "Realidad virtual, mímesis y simulación". CIC. Cuadernos de información y comunicación, vol. 16, pp. 59-81.

CASTRONOVA, Edward (2005). Synthetic Worlds: The Business and Culture of Online Games. Chicago: University of Chicago Press.

CLIFFORD, James (2008): Itinerarios transculturales. Barcelona: Gedisa.

CONSALVO, Mia; BEGY, Jason (2012): "What Happens at the End of the World? An MMOG's Closure and Player Responses". The Philosophy of Computer Games Conference. Madrid: 2012.

COSER, Lewis A. (1956). The functions of social conflict. Glencoe: The Free Press. ECHEVERRÍA, Javier (2000). Un mundo virtual. Barcelona: Plaza \& Janés.

HINE, Christine (2004). Etnografía virtual. Barcelona. Editorial UOC.

JONES, Steven G. (ed.) (1995). CyberSociety: Computer-Mediated Communication and Community. Thousand Oaks, CA: Sage Publications. 
JONES, Steven G. (ed.) (2003). Cibersociedad 2.0. Barcelona. Editorial UOC.

KLASTRUP, Lisbeth (2003). Towards a Poetics of Virtual Worlds. PhD diss., IT University: Copenhagen.

KLASTRUP, Lisbeth; TOSCA, Susana (2004). “Transmedial Worlds. Rethinking Cyberworld Design". III International Conference on Cyberworlds (CW 2004), IEEE Computer Society, 18-20. Tokyo.

LÉVY, Pierre (1999). ¿Qué es lo virtual? Barcelona: Paidós.

LÉVY, Pierre (2007). Cibercultura. La cultura de la sociedad digital. México: Anthropos.

MALABY, Thomas M. (2009). Making Virtual Worlds. Linden Lab and Second Life. Ithaca, NY: Cornell University Press.

MANOVICH, Lev (2005). El lenguaje de los nuevos medios de comunicación. La imagen en la era digital. Barcelona. Paidós.

MANOVICH, Lev (2013). El software toma el mando. Barcelona: UOCpress.

MARCUS, George E. (1995). "Ethnography in/of the World System: The Emergence of Multi-Sited Ethnography". Annual Review of Anthropology, 24, pp. 95-117.

McLUHAN, Marshall (1996). Comprender los medios de comunicación. Las extensiones del ser humano. Barcelona: Paidós.

MURRAY, Janet H. (1999). Hamlet en la Holocubierta. Barcelona: Paidós.

NARDI, Bonnie A. (2010). My Life as a Night Elf Priest. Ann Harbor. The University of Michigan.

PEARCE, Celia (2009). Communities of Play. Emergent Cultures in Multiplayer Games and Virtual Worlds. Cambridge. The MIT Press.

PEÑAMARÍN, Cristina (2007). "El hogar y el mundo. La imaginación en los discursos informativos y publicitarios". CIC. Cuadernos de información y comunicación, vol. 12, pp. 169- 184.

SIMMEL, Georg (1955). Conflict. Glencoe: The Free Press.

TAYLOR, T. L. (2006). Play Between Worlds. Cambridge: MA. MIT Press.

VENTRELLA, Jeffrey (2011). Virtual Body Language. The History and Future of Avatars: How Nonverbal Expression is Evolving on the Internet. Eyebrain Books. 